http://jmscr.igmpublication.org/home/ ISSN (e)-2347-176x ISSN (p) 2455-0450

crossref DOI: https://dx.doi.org/10.18535/jmscr/v7i9.94

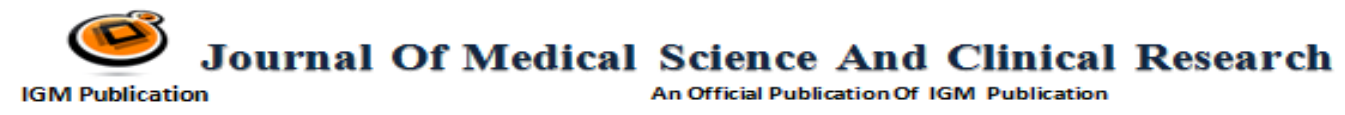

Original Article

\title{
Phenotype and Genotype Prevalence of Carbapenemase genes in bacterial isolates from lower respiratory tract specimens in a tertiary care centre in central Kerala
}

Authors

Sheeba K Thomas ${ }^{1}$, Shoba Kurian Pulikottil ${ }^{2}$, Kiran $\mathbf{N}^{3}$, Leah Thomas ${ }^{4}$, Molly Antony ${ }^{5}$

${ }^{1}$ Assistant Professor, Department of Microbiology, Government Medical College, Kottayam, Kerala, India

${ }^{2}$ Professor and Head, Department of Microbiology, Government Medical College, Kottayam, Kerala, India

${ }^{3}$ Assistant Professor, Department of Pulmonology, Government Medical College, Kottayam, Kerala, India

${ }^{4}$ Junior Resident, Department of Microbiology, Government Medical College, Kottayam, Kerala, India

${ }^{5}$ Senior Scientific Officer, Department of Microbiology, SCTIMST, Trivandrum, Kerala, India

\begin{abstract}
Background: Carbapenem-resistant Enterobacteriaceae (CRE) represent a global public health threat. Emergence of carbapenems-resistant organisms represents a serious challenge for antimicrobial therapy. Among the widely recognized types of Carbapenemases, New Delhi B-lactamase (NDM) and Klebsiella pneumoniae carbapenemase (KPC) are the most important enzymes.

Objective: The aim of this research is to determine the genotypic prevelance of NDM and KPC genes among Gram negative organisms with high-level Carbapenem resistance from respiratory tract specimens at Government Medical College Kottayam using RT-PCR .

Method: A total of 1216 respiratory tract specimens including sputum, bronchoalveolar lavage and tracheal aspirate were collected during June 2017 to November 2017. The susceptibility of all isolates to Meropenem was selected by disc diffusion method according to Clinical Laboratory Standards Institute guidelines. Isolates with intermediate susceptibility to Meropenem and Meropenem resistant isolates were further selected for genotyping. The presence of genes coding for Carbapenemases such as bla $a_{N D M-1}$ and bla $_{K P C}$ was detected by polymerase chain reaction.

Results: Out of 290 isolates, 40 isolates are resistant to Carbapenems phenotypically. 14\% (31/220) were Klebsiella pneumonia and $12.8 \%$ (9/70) were Escherichia coli. Genotypic study shows 3 out of the 40 isolates possessed NDM gene and all three were Klebsiella pneumoniae. No KPC gene was located in all 40 isolates. Escherichia coli did not posess both NDM or KPC genes.

Conclusion: Carbapenem resistance is due to injudicious use of higher antibiotics, therefore to prevent this, periodic surveillance of sputum cultures, antibiotic resistance pattern and regular updates on antibiotic policy guidelines is the best strategy.

Keywords: Carbapenem-resistant Enterobacteriaceae (CRE), $\quad$ Carbapenemase- $\quad$ producing Enterobacteriaceae (CPE), Klebsiella pneumonia, Escherichia coli, New Delhi $\beta$-lactamase (NDM), Klebsiella pneumoniae carbapenemase (KPC).
\end{abstract}

\section{Introduction}

Antibiotic resistance is a tremendous health problem. This includes the resistance to
Carbapenems which was considered as the last resort for Enterobacteriaceae infections ${ }^{1}$. Carbapenems, among the beta-lactams, are the 
most effective against Gram-positive and Gramnegative bacteria, their unique molecular structure due to the presence of a Carbapenem together with the beta-lactam ring. This combination confers exceptional stability against most betalactamases (enzymes that inactivate beta-lactams) including Ampicillin and Carbenicillin (AmpC) and the Extended Spectrum beta-lactamases (ESBLs) $^{2}$. Carbapenemase- producing Enterobacteriaceae (CPE) are well known to cause many serious infections resulting in increasing mortality rate, treatment cost, and prolonged hospitalization. ${ }^{3}$ It has developed due to the acquisition of genes encoding Carbapenemases (carbapenem hydrolyzing enzymes). Three classes of carbapenemases (A, B and D) are involved in the Carbapenem resistance (i) class A Klebsiella pneumoniae carbapenemase (KPC) (ii) class $\mathrm{B}$, Metallo- $\beta$-lactamases (MBLs) such as Verona integron Metallo-beta-lactamase (VIM), Imipenemase Metallo-beta-lactamase (IMP) and New Delhi Metallo-beta-lactamase (NDM) and (iii) class $\mathrm{D}$, Oxacillin hydrolyzing betalactamases (OXA). These bacteria have spread rapidly through mobilisable genetic elements for example, plasmid IncX3, IncA/C2; transposon Tn4401, Tn125 , or class I Integron. ${ }^{4}$

In 2017, the World Health Organization published a list of superbugs including CRE. Carbapenemase production and ESBL/AmpC $\beta$ lactamase production coupled with porin loss or efflux pump were the common ways that Enterobacteriaceae become resistant to carbapenems. New Delhi Metallo- $\beta$-lactamase-1 (NDM-1) was found in Asia with the highest frequency; Klebsiella pneumoniae carbapenemase (KPC) was the most popular enzyme causing carbapenem resistance, especially KPC-2 in USA. Among various methods, PCR, real-time PCR, and DNA sequencing are the gold standards for carbapenemase-encoding genes detection. ${ }^{4}$

This study attempts to trace NDM and KPC carbapenamases in respiratory tract samples in tertiary care centre at Kottayam in central Kerala, India. The primers were used accordingly, and the genotypes among MDR strains of bacteria of the family Enterobactericeae were determined.

\section{Materials and Methods \\ Isolation of bacterial Isolates}

A total of 1216 respiratory tract specimens namely sputum, bronchoalveolar lavage and tracheal aspirate were collected during June 2017 to November 2017. Culture yielded 290 Gram negative isolates which were selected for processing. All isolates were plated on blood agar, MacConkey agar and chocolate agar and identified in accordance with the biochemical standard assay methods.

\section{Antibiotic Susceptibility Testing of Isolates}

The susceptibility of all isolates to antibiotics were selected by disc diffusion method according to Clinical Laboratory Standards Institute guidelines. The drugs tested include Ampicillin, Cephalexin, Cefotaxime, Gentamicin, Amikacin, Ciprofloxacin, Cefoperazone-Sulbactum, Piperacillin-Tazobactum and Meropenem. Isolates with intermediate susceptibility to Meropenem and Meropenem resistant isolates were selected. The control strains used were Klebsiella pneumoniae 700603 and E coli ATCC 25922.

\section{Detection of Carbapenemase by phenotypic methods}

Table 1: Carbapenamase detection(CLSI 2016) ${ }^{8}$

\begin{tabular}{|l|c|c|c|c|}
\hline $\begin{array}{l}\text { Antimicrobial } \\
\text { Agent }\end{array}$ & $\begin{array}{c}\text { Disc } \\
\text { Content }\end{array}$ & $\begin{array}{c}\text { Suscepti } \\
\text { ble }\end{array}$ & Intermediate & Resistant \\
\hline Meropenem & $10 \mu \mathrm{g}$ & $\geq 23 \mathrm{~mm}$ & $20-22 \mathrm{~mm}$ & $\leq 19 \mathrm{~mm}$ \\
\hline
\end{tabular}

Table 2

\begin{tabular}{l}
\hline 1216 samples from Respiratory tract- Sputum, FOB wash \\
and Tracheal aspirate \\
\hline 290 isolates- Klebsiella pneumoniae and E coli \\
\hline Phenotyping of 40 isolates by CLSI method \\
\hline $\begin{array}{l}\text { Genotyping of } 40 \text { isolates for NDM and KPC } \\
\text { carbapenamases genes by RT-PCR }\end{array}$ \\
\hline
\end{tabular}

Table 3: Phenotype Prevalence of carbapenamases among Gram negative rods

\begin{tabular}{|l|c|c|}
\hline Nature of Isolate & $\begin{array}{c}\text { Number of } \\
\text { Isolates }\end{array}$ & $\begin{array}{c}\text { Number of Meropenem } \\
\text { resistant Isolates }\end{array}$ \\
\hline Klebsiella pneumoniae & $220(82 \%)$ & $31(14 \%)$ \\
\hline E coli & $70(18 \%)$ & $9(12.8 \%)$ \\
\hline Total & $290(100 \%)$ & $40(13.7 \%)$ \\
\hline
\end{tabular}


PCR Analysis of the Carbapenem-Resistant Isolates

Total DNA was extracted from the 40 carbapenem-resistant $K$. pneumoniae isolates using Genomic DNA purification Kit. The extracted DNA was used in real time PCR as per CDC guidelines. The presence of genes coding for carbapenemases such as $b l a_{\mathrm{NDM}-1}$ and $b l a_{\mathrm{KPC}}$ was detected by polymerase chain reaction. DNA template preparation and PCR amplification were carried out in thermal cycler of Applied Biosystems 7500 Fast RT-PCR system.

Table 4: Genotype Prevalence of carbapenamases among Gram negative rods

\begin{tabular}{|l|c|c|}
\hline Carbapenamases & $\begin{array}{c}\text { Klebsiella pneumoniae } \\
31(14 \%)\end{array}$ & $\begin{array}{c}\text { E coli } \\
9(12.8 \%)\end{array}$ \\
\hline bla $_{\mathrm{NDM}-1}$ & 3 & 0 \\
\hline bla $_{\mathrm{KPC}}$ & 0 & 0 \\
\hline
\end{tabular}

\section{Results:}

The specimens collected from lower respiratory tract infections include sputum, bronchoalveolar lavage and tracheal aspirate as in Table 1. The most common specimen was sputum accounting for $76 \%$ of specimens followed by bronchoalveolar lavage and tracheal aspirate. $28 \%$ of specimens were from Pulmonology unit, $22 \%$ from Cardiothoracic unit and 20\% from critical care unit- both medical and surgical. The remaining $30 \%$ of specimens were from Medicine, Nephrology and Neurosurgery units. $77 \%$ of specimens were from males and $23 \%$ were from females.

Table 3 shows the prevalence of meropenem resistance among 31 isolates of Klebsiella pneumoniae and 9 of E coli of Enterobactericeae. Thus 40 of the total isolates are showing meropenem resistance. Table 4 shows the prevalence of carbapenamases among Gram negative rods as present in Klebsiella pneumoniae and $E$ coli based on the presence of genes coding for carbapenemases such as $b l a_{\mathrm{NDM}-1}$ and $b l a_{\mathrm{KPC}}$ detected by polymerase chain reaction. Of the total 40 multidrug resistant isolates only 3 isolates were positive for carbapenamases which was positive for the presence of the gene NDM. No $\mathrm{KPC}$ gene positive isolates were isolated.

\section{Discussion}

Carbapenems have been kept as the last antibiotic choice for the treatment of severe infections; however, the development of carbapenem resistance significantly compromises their activities. ${ }^{1}$ In this study, out of the 1216 samples from Respiratory tract; 290 isolates $(23.8 \%)$ were obtained out of which Klebsiella pneumoniae were $220(82 \%)$ and $70(18 \%)$. This is similar to the study by Gunjal et al where $75.86 \%$ Klebsiella pneumoniae and $24.13 \%$ E coli were isolated from sputum samples. ${ }^{9}$ Shilpa K et al showed that among 128 Klebsiella pneumoniae from sputum samples in a tertiary care hospital, 30 (23\%) were Klebsiella pneumonia. ${ }^{10}$ In another study by Babakani et al $36.3 \%$ of Klebsiellae were isolated from sputum samples. ${ }^{11}$

In this study 189 Klebsiella pneumoniae (85.9\%) and $61 \mathrm{E}$ coli $(87.1 \%)$ isolates were sensitive to meropenem. This corresponds to the study by Saha et al with $83.33 \%$ meropenem sensitivity for E.coli isolated from sputum samples ${ }^{12}$ and to that by Sharma et al with $90 \%$ carbapenem sensitivity for Klebsiella species and $80 \%$ sensitivity for E.coli. ${ }^{13}$

Phenotypic screening was done as per CLSI guidelines of 2017, 40 isolates with intermediate susceptibility or resistance to meropenem were obtained out of which Klebsiella pneumoniae were $31(14 \%)$ and E coli $9(12.8 \%)$. These findings are low as compared to the study by $\mathrm{S} P$ Gunjal et al where $36.36 \%$ Klebsiella pneumoniae and $85.71 \% \mathrm{E}$ coli were resistant to meropenem. ${ }^{9}$ But it corresponds to the study by Sharma $\mathrm{P}$ et al with $10 \%$ carbapenem resistance for Klebsiella species and 20\% for E.coli ${ }^{13}$ and a study by Saha AK et al with $16.7 \%$ meropenem resistance for $\mathrm{E}$ coli. ${ }^{12}$ Among these, more than half were isolated from respiratory specimens (62.9\%), including 75 (30.9\%) from sputum, 38 $(15.6 \%)$ from endotracheal aspirate (ETA), and 40 (16.4\%) from broncho alveolar lavage fluid and 
similar findings are also seen in the study by $\mathrm{Li} \mathrm{Y}$ et al. ${ }^{14}$

In this study out of the 31 resistant Klebsiella pneumoniae isolates only 3 bla $a_{\mathrm{NDM}-1}$ was detected and bla $\mathrm{KPC}_{\mathrm{K}}$ was absent. bla $\mathrm{NDM}_{1}$ and $b l a_{K P C}$ were both absent among E.coli. In a study by Barwa et al similar findings were noted with five isolates contained bla $\mathrm{NDM}^{-1}$ isolated among Klebsiella pneumoniae with elevated resistance to carbapenems. ${ }^{1,15,16}$

Arijit Bora et al showed that $8.7 \%$ NDM-1 were detected among 219 non-duplicated $K$ pneumoniae isolates in their study. ${ }^{16}$ This corresponds to our study in which NDM-1 (9.7\%) gene was isolated out of the 31 resistant Klebsiella pneumoniae isolates. However, in this study none of our isolates were positive for bla $a_{\mathrm{KPC}}$. Our finding was in agreement with that of Mohan B et al and Nagaraj $\mathrm{S}$ et al who also did not find $b l a_{\mathrm{KPC}}$ in any of their carbapenem resistant isolates. ${ }^{17,18}$

Carbapenem resistance may also be due to diminished permeability of the outer membrane, hyperproduction of ESBLs and AmpC associated with alteration or loss of porins or due to an active efflux pump system.

\section{Conclusion}

Carbapenem resistance is due to injudicious and empiric therapy with the higher generation of antibiotics in the hospitals. Therefore, previous usage of antibiotics should be the influential factor for understanding the elements of antimicrobial resistance. Periodic antimicrobial surveillance in case of hospital acquired infections is regularly needed to update the guidelines on proper choice of organism specific as well as empiric antibiotics.

\section{Conflict of Interest: Nil}

\section{Acknowledgement:}

This study was done as State Board of Medical Research Project funded by Government of Kerala.

\section{References}

1. Barwa R, Shaaban M. Molecular Characterization of Klebsiella pneumoniae Clinical Isolates with Elevated Resistance to Carbapenems. Open Microbiol J. 2017 Jul 31;11:152-9.

2. Meletis G. Carbapenem resistance: overview of the problem and future perspectives. Ther Adv Infect Dis. 2016 Feb;3(1):15-21.

3. Gupta N, Limbago BM, Patel JB, Kallen AJ. Carbapenem-Resistant Enterobacteriaceae: Epidemiology and Prevention. Clin Infect Dis. 2011 Jul 1;53(1):60-7.

4. Hoang CQ, Nguyen HD, Vu HQ, Nguyen AT, Pham BT, Tran TL, et al. Emergence of NDM and KPC Production by Escherichia coli and Klebsiella pneumoniae in Southern Vietnam and Appropriate Methods of Detection: A Cross-Sectional Study [Internet]. BioMed Research International. 2019 [cited 2019 Jul 20].

5. Management-cre-ltcf-040516.pdf [Internet]. [cited 2019 Jul 21].

6. Codjoe FS, Donkor ES. Carbapenem Resistance: A Review. Med Sci [Internet]. 2017 Dec 21 [cited 2019 Jul 21];6(1).

7. Logan LK, Renschler JP, Gandra S, Weinstein RA, Laxminarayan R. Carbapenem-Resistant Enterobacteriaceae in Children, United States, 1999-2012 Volume 21, Number 11-November 2015 - Emerging Infectious Diseases journal CDC. [cited 2019 Jul 21];

8. Clinical Laboratory Standards Institute 2016 edition.

9. S P Gunjal, Prasad Niranjan Gunjal, Nagaraju Vanaparthi, Kher Sudheer. Carbapenem resistance profile in $\mathrm{E}$ coli and $\mathrm{K}$ pneumoniae in a tertiary care centre at Ahmedanagar, Maharashtra. Int J Med Res Health Sci. 2014 Mar;3(2):424-7.

10. K S, Thomas R, Ramyashree A. Isolation and Antimicrobial sensitivity pattern of 
Klebsiella pneumoniae from sputum samples in a tertiary care hospital. Int $\mathbf{J}$ Biomed Adv Res. 2016 Feb 28;7(2):53-7.

11. Babakhani S, shokri S, R. Nazer M, Kazemi M. Comparison Frequency and Determination Antibiotic Resistance Pattern of Klebsiella SPP. Isolated from Nosocomial Infection in Khorramabad Shohadaye Ashayer Hospital. Bull Environ Pharmacol Life Sci. 2014 Nov 1;3:149-54.

12. Saha AK, Dhar P. Spectrum of Antimicrobial Sensitivity of Escherichia Coli in Sputum in a Tertiary Medical Centre in Kolkata, West Bengal, 7 Years' Experience. 2017;4(10):4.

13. Sharma P, Narula S, Sharma K, Kumar N, Lohchab K, Kumar N. Sputum bacteriology and antibiotic sensitivity pattern in COPD exacerbation in India. Egypt J Chest Dis Tuberc. 2017 Oct 1;66(4):593-7.

14. Li Y, Shen H, Zhu C, Yu Y. CarbapenemResistant Klebsiella pneumoniae Infections among ICU Admission Patients in Central China: Prevalence and Prediction Model [Internet]. BioMed Research International. 2019 [cited 2019 Aug 30]. Available from: https://www.hindawi.com/journals/bmri/2 019/9767313/

15. M Uma Maheswari, Appalaraju. Molecular Detection and Subtyping of New Delhi Metallobetalactamases (NDM1) in Clinical Isolates of Escherichia coli and Klebsiella pneumoniae in a Tertiary Care Hospital, South India. Int J Curr Microbiol Appl Sci. 2017;6(5):2264-70.

16. Arijit Bora, Giasuddin Ahmed. Detection of NDM-1 in Clinical Isolates of Klebsiella Pneumoniae from Northeast India. J Clin Diagn Res JCDR. 2012 Jun;6(5):794-800.

17. Mohan B, Hallur V, Singh G, Sandhu HK, Appannanavar SB, Taneja N. Occurrence of bla NDM-1 $_{2} \&$ absence of bla $\mathrm{KPC}_{\text {genes }}$ encoding carbapenem resistance in uropathogens from a tertiary care centre from north India. Indian J Med Res. 2015 Sep;142(3):336-43.

18. Nagaraj S, Chandran SP, Shamanna P, Macaden R. Carbapenem resistance among Escherichia coli and Klebsiella pneumoniae in a tertiary care hospital in south India. Indian J Med Microbiol. 2012 Jan 1;30(1):93. 